\title{
Effects of USD-Euro parity on a small open economy: evidence from Turkey
}

\section{Hakan Berument \& Eray M. Yucel}

To cite this article: Hakan Berument \& Eray M. Yucel (2008) Effects of USD-Euro parity on a small open economy: evidence from Turkey, Applied Economics, 40:16, 2165-2174, DOI: $10.1080 / 00036840600949322$

To link to this article: http://dx.doi.org/10.1080/00036840600949322

$$
\text { 曲 Published online: } 11 \text { Apr } 2011 .
$$

Submit your article to this journal

Цll Article views: 51

Q View related articles ¿ 


\title{
Effects of USD-Euro parity on a small open economy: evidence from Turkey
}

\author{
Hakan Berument ${ }^{\mathrm{a}}$ and Eray M. Yucel ${ }^{\mathrm{b}, *}$ \\ ${ }^{a}$ Department of Economics, Bilkent University, 06800 Ankara, Turkey \\ ${ }^{\mathrm{b}}$ Research and Monetary Policy Department, Central Bank of the Republic \\ of Turkey, Istiklal Cad. No. 10, 06100 Ankara, Turkey
}

This study assesses the effect of USD-Euro parity on a small open economy where exports are predominantly denominated in Euros and imports are denominated in USD. Empirical evidence from Turkey suggests that a positive change in the USD value of the Euro appreciates the local currency, decreases inflation and increases output.

\section{Introduction}

USD-Euro parity is one of the most widely followed variables in financial markets. Its sizable movements (Fig. 1) have often been discussed in light of their implications on developed economies. In this article, we will assess the implications of USD-Euro parity (the US dollar value of the Euro) on a small open economy (SOE) under an unbalanced trade denomination, where the exports are realized mainly in one currency and imports in another.

In this article, based on an illustrative model of the transmission of external parity movements to SOE dynamics, the effects of USD-Euro parity are analysed using Turkish data. Turkey is an SOE, and the relative movements of these major currencies are expected to affect its major macroeconomic variables. These effects may occur through the channels of the real exchange rate and/or the terms of trade. In fact, neither overlaps the other in a oneto-one fashion nor are they isolated from each other. In either of these channels, net exports will respond to USD-Euro parity as a result of the change in the relative prices of tradables. The theoretical transmission mechanism that we propose is demonstrated with an illustrative model in Appendix, where USD-Euro parity enters the system by affecting net exports and domestic absorption.

For Turkey, the relationship between USD-Euro parity and the real exchange rate is relevant for two reasons. Firstly, Turkey is an SOE and cannot affect USD-Euro parity, but the reverse is true. Therefore, our investigation focuses only on the effects of exogenous USD-Euro parity shocks on domestic macroeconomic performance, rather than looking in the opposite direction. Secondly, the currency composition of Turkey's trade is not balanced. For instance, in 2004, 50.1\% of Turkish exports were denominated in Euros and $42.9 \%$ in USD. However, the composition of imports is such that the Euro and the USD have respective shares of 40.3 and $55.0 \%$. Moreover, Turkey is a net exporter of tourism services and receives revenue from tourism, mostly originating from Europe. This further enhances the effects of USD-Euro parity on the domestic economy. Hence, a change in USD-Euro parity is expected to have sizable effects on Turkish economic performance.

*Corresponding author. E-mail: eray.yucel@gmail.com 


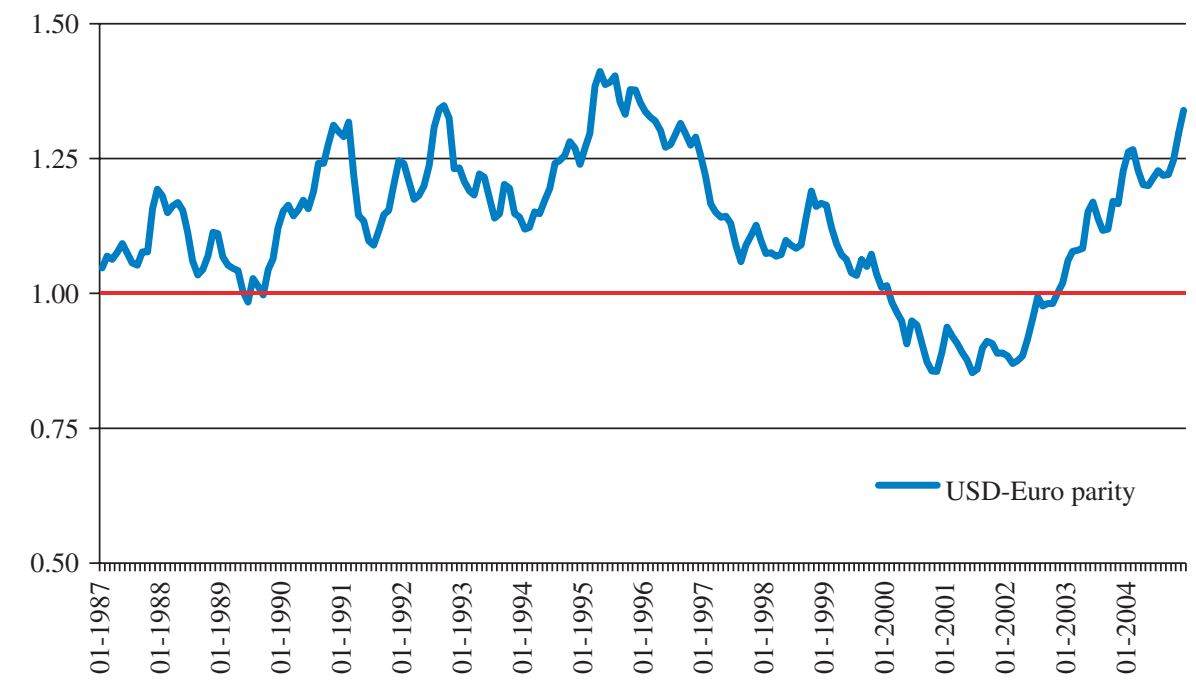

Fig. 1. USD-Euro parity ${ }^{\mathrm{a}}$

Notes: ${ }^{a}$ USD-Euro parity is measured as the USD value of the Euro. Thus, an increase in the parity figures shows appreciation of the Euro against the USD.

In the literature, to the best of our knowledge, Berument and Dincer (2005), is the only study specifically considering the effects of USD-Euro parity on economic performance for an SOE. It looks at the effects of USD-Euro parity on Turkish trade balance and argues that an increase in the USD value of the Euro appreciates local currency and increases net exports.

Spatafora (2003), looked at a similar issue by investigating the effects of $\mathrm{G}-3^{1}$ exchange rate volatility (not the level of the exchange rate as we do, but its volatility) on developing economies. ${ }^{2} \mathrm{He}$ noted that even after the collapse of the Bretton Woods system, one-half to two-thirds of all developing countries actually continued pegging their exchange rates to the currencies of industrial countries. Therefore, the volatility of the major industrial countries' currencies affects the volatility of the developing countries' exchange rates. Then he argued that exports are affected positively (not statistically significant) and imports are affected negatively (significant) for the case of emerging markets. Nevertheless, Spatafora (2003), employed a broad panel of countries in his analysis and did not focus on any specific country.

In the current study, we assess the relationship within the vector auto regressive (VAR) models framework with block exogeneity to account for the exogeneity of USD-Euro parity. In particular, we allow USD-Euro parity to affect economic performance, but not vice versa. In order to capture the dynamics of the domestic economy - similar to Kamin and Rogers (2000) and Berument and Pasaogullari (2003) - we employ three variable VAR that include the real exchange rate, the inflation rate and the real gross domestic product (GDP). ${ }^{3}$

${ }^{1}$ G-3 describes the three major currency areas, namely the United States, Japan and the Euro areas.

${ }^{2}$ The impact that large currencies' exchange rate movements have on advanced economies has been investigated and generally found to be small (World Economic Outlook, April 2002, Appendix 1.2; World Economic Outlook, May 2001, Appendix II). ${ }^{3}$ There are several studies in the literature, particularly Akinlo and Odusola (2003), Christopoulos (2004), Upadhyaya et al. (2004) and Berument et al. (2006) for the effect of exchange rate on domestic economic performance. Among these, the first one assesses the link between exchange rate depreciation and economic growth for Nigeria within a structural VAR framework; the authors argue that Nigeria should encourage real appreciation in order to deflate prices quickly and enhance economic activity. They also highlight that such a policy must be considered in a cautious manner; without pushing the exchange rate beyond its equilibrium level and without discouraging domestic production in favour of imported commodities. On the other hand, Christopoulos (2004) examines a similar relationship for eleven Asian countries using panel data techniques. The evidence is interestingly mixed: in nearly half of the sample countries, depreciation exerts a negative pressure on output growth in the long-run, but it improves growth prospects for some others. Upadhyaya et al. (2004) use a panel data analysis to consider the transmission from exchange rate adjustment to output dynamics in Greece and Cyprus and conclude that exchange rate depreciation is expansionary in the short run, though it is neutral in the medium and long-run. Finally, Berument et al. (2006) study the transmission from Japanese economic performance to the Indonesian economy. In addition to their key findings, they also report as a side issue that real exchange rate depreciation accelerates inflation and decelerates growth in Indonesia. All in all, there is little consistent pattern across economies and across empirical studies, yet each study contains clues about the exchange rate-output relationship. 
The response of the real exchange rate to USD-Euro parity indirectly reveals whether there is an actual improvement in trade competitiveness and thus income. The empirical evidence provided in this article suggests that an increase in the USD value of the Euro appreciates the real exchange rate, decreases inflation and increases output.

The analysis and findings of this article are important: the case of Turkey with regard to changes in USD-Euro parity establishes a benchmark example for similar 'emerging market economies' by demonstrating the extent of the exposure of an SOE to the relative movements of two big currencies. The focus of the current study on 'big currencies' distinguishes it from the earlier empirical research (see footnote 3).

The article is structured as follows: Section II presents the data and the results of our bivariate analysis. In Section III, our VAR specification is given. We present and interpret the estimated impulse-responses in Section IV. Finally, Section V concludes the article.

\section{Data and Bivariate Analysis}

In this section, we first describe the data sources and give the definitions of our variables. Then, we provide the cross-correlations, unit-root and cointegration tests for these variables. The data were obtained from the Central Bank of the Republic of Turkey ${ }^{4}$ with the exception of the GDP deflator, which was taken from the International Financial Statistics of the International Monetary Fund. ${ }^{5}$ Our data set covers the period from the first quarter of 1987 to the last quarter of 2004. In our analysis, Parity is the natural logarithm of the USD value of the Euro. The real exchange rate (rexch) is computed as the natural logarithm of the wholesale price index $(1994=100)$ deflated Turkish lira value of the USD. ${ }^{6,7}$ The measure of the output $(y)$ is the natural logarithm of the real GDP. Inflation (Inf) is calculated as the quarterly percentage change in the GDP deflator.
In Table 1, the cross-correlations of Parity with $y$, rexch and Inf are reported from 0 to 8 quarter lags, variables being used in the form of levels and first differences, as well as deviations from linear, quadratic, cubic and HP trends. Table 1 suggests that when the variables are considered in their levels, the cross-correlation between Inf and Parity is significantly ${ }^{8}$ negative both contemporaneously as well as when Parity lags inflation by four quarters. The cross-correlation between rexch and Parity is negative and significant at lags of 3,2,1 and 0. For $y$ and Parity, the cross-correlations are significant and positive for 2,1 and 0 lags. When we look at the cross-correlations between the firstdifferenced series, it can be seen that there is a negative association between Inf and Parity contemporaneously; that is, the amount of increase in inflation is negatively correlated with the rate of appreciation of the Euro against the USD. At a lag of 4 , the relationship is negative and significant, whereas at one lag of parity the relationship is positive. The relationship between rexch and Parity is significantly positive only contemporaneously. In other words, the rate of real appreciation of the Turkish lira and the rate of appreciation of the Euro against the USD are positively associated at zero lags. The correlation between $y$ (i.e. the growth rate of real income after the first differencing) and Parity (the rate of appreciation of the Euro against the USD) is negative and statistically significant when $y$ leads Parity by 3 and 7 lags.

We also assessed the cross correlations between the deviations of our variables from their respective linear trends estimated via ordinary least squares (OLSs). These figures suggest that Inf and Parity are significantly negatively correlated contemporaneously and at a lag of 4 . The variables rexch and Parity are negatively correlated at lags of 3 and 4 . There is no statistically significant association between deviations from the linear trend of $y$ and Parity. Repeating the same exercise using the deviations of our series from their quadratic, cubic and HP-filtered trends, we observe no statistically significant cross-correlations among our variables

\footnotetext{
${ }^{4}$ Accessible at: http://tcmbf40.tcmb.gov.tr/cbt.html

${ }^{5}$ Accessible at: http://ifs.apdi.net/imf

${ }^{6}$ For USD-Euro parity and the TL/USD exchange rate raw data, we have used the period average values. For the time period before the circulation of the Euro, USD-Euro parity is computed using the Euro to DEM (Deutsche Mark) conversion factor of 1.95 and the DEM/USD period average exchange rate. We did not use the US CPI while computing the real exchange rate since Turkish inflation is remarkably high compared to that of the US. For instance, the average annual consumer price inflation in Turkey and the United States for 1987 to 2003 are nearly 69 and 3\%, respectively.

${ }^{7}$ We have computed the real exchange rate based on the Turkish lira value of the US dollar (instead of the Euro) following the usual convention in the empirical literature; see for instance Kamin and Rogers (2000) or Berument and Pasaogullari (2003).

${ }^{8}$ The level of statistical significance is $5 \%$, unless otherwise noted.
} 
Table 1. Cross-correlations of parity and other variables of concern ${ }^{a}$

\begin{tabular}{|c|c|c|c|c|c|c|c|c|c|}
\hline \multirow[b]{2}{*}{$\operatorname{Lag}^{\mathrm{b}}$} & \multicolumn{3}{|l|}{ Levels } & \multicolumn{3}{|c|}{ First differences } & \multicolumn{3}{|c|}{ Deviations from linear trend } \\
\hline & $\operatorname{Inf}$ & rexch & $y$ & Inf & rexch & $y$ & $\operatorname{Inf}$ & rexch & $y$ \\
\hline 0 & $-0.357^{*}$ & $-0.280 *$ & $0.324 *$ & $-0.323 *$ & $0.197 *$ & -0.046 & $-0.300^{*}$ & -0.166 & -0.040 \\
\hline 1 & $-0.220 *$ & $-0.248^{*}$ & $0.332 *$ & $0.203 *$ & 0.101 & 0.172 & -0.136 & -0.162 & 0.069 \\
\hline 2 & $-0.209 *$ & $-0.247^{*}$ & $0.271^{*}$ & 0.020 & -0.083 & 0.115 & -0.105 & -0.191 & 0.043 \\
\hline 3 & $-0.215^{*}$ & $-0.235^{*}$ & 0.156 & 0.104 & -0.093 & $-0.270^{*}$ & -0.133 & $-0.212 *$ & -0.102 \\
\hline 4 & $-0.288^{*}$ & -0.192 & 0.154 & $-0.262 *$ & -0.141 & 0.027 & $-0.252 *$ & $-0.194 *$ & -0.041 \\
\hline 5 & -0.193 & -0.133 & 0.150 & 0.081 & 0.046 & 0.176 & -0.151 & -0.148 & 0.034 \\
\hline 6 & -0.145 & -0.096 & 0.076 & 0.055 & -0.071 & 0.060 & -0.083 & -0.128 & -0.024 \\
\hline 7 & -0.136 & -0.045 & -0.032 & 0.030 & -0.187 & $-0.232 *$ & -0.086 & -0.099 & -0.163 \\
\hline \multirow[t]{2}{*}{8} & -0.146 & 0.028 & -0.029 & -0.183 & 0.178 & -0.007 & -0.118 & -0.042 & -0.113 \\
\hline & \multicolumn{3}{|c|}{ Deviations from quadratic trend } & \multicolumn{3}{|c|}{ Deviations from cubic trend } & \multicolumn{3}{|c|}{ Deviations from HP trend } \\
\hline 0 & -0.121 & -0.131 & 0.036 & -0.121 & -0.116 & 0.031 & -0.125 & -0.072 & 0.002 \\
\hline 1 & 0.079 & -0.096 & 0.142 & 0.081 & -0.099 & 0.144 & 0.103 & -0.058 & 0.138 \\
\hline 2 & 0.044 & -0.114 & 0.079 & 0.050 & -0.143 & 0.083 & 0.075 & -0.124 & 0.082 \\
\hline 3 & 0.005 & -0.103 & -0.084 & 0.009 & -0.151 & -0.084 & 0.029 & -0.152 & -0.102 \\
\hline 4 & -0.156 & -0.045 & 0.019 & -0.156 & -0.124 & 0.020 & -0.157 & -0.130 & 0.021 \\
\hline 5 & -0.018 & 0.043 & 0.084 & -0.020 & -0.040 & 0.091 & -0.006 & -0.042 & 0.113 \\
\hline 6 & 0.020 & 0.098 & -0.025 & 0.022 & 0.011 & -0.016 & 0.044 & 0.003 & 0.006 \\
\hline 7 & 0.004 & 0.187 & -0.180 & 0.004 & 0.092 & -0.174 & 0.025 & 0.087 & -0.166 \\
\hline 8 & -0.032 & $0.324^{*}$ & -0.107 & -0.035 & $0.263^{*}$ & -0.101 & -0.021 & $0.271^{*}$ & -0.079 \\
\hline
\end{tabular}

Notes: ${ }^{\text {a }}$ The table shows the cross-correlations between Parity and Inf, rexch and $y$. The transformation above each three-column block is applied to all variables included in that block.

${ }^{\mathrm{b}} \mathrm{Lag}$ refers to the number of periods by which USD-Euro parity lags a series.

*Indicates that the cross-correlation figure is significant at the $10 \%$ level of significance. SDs of cross-correlations are computed as $1 / \sqrt{T}$, where $T$ is the sample size.

of concern, except that there is a significant and positive association between rexch and Parity when the former leads the latter by 8 lags. All in all, Table 1 provides statistical evidence; that allows us to argue that movements of Parity lead to changes in the domestic economy, even before we get into a more sophisticated modelling of the variables of interest.

The unit-root tests of Inf, Parity, rexch and $y$ are reported in Table 2. We have performed augmented Dickey-Fuller (ADF) tests for each variable in two different set-ups. In the first one, we include the constant term but exclude the trend term, whereas both are included in the second one. The null hypothesis is such that the variable of concern includes a unit-root. In Table 2, the ADF test statistics for the first differences of our variables are also reported. For each test presented in this table, the optimal lag length of the ADF equation is obtained by minimizing the modified-Schwarz criterion. Based on the ADF test statistics, we fail to reject the hypothesis of a unit-root for all of Parity, rexch, Inf and $y$ in levels. This observation is robust up to the inclusion of the trend in the ADF test equations. Consequently, we can conclude that all our series include unit-roots. It can be seen that the unit-roots disappear when the test is conducted for the first-differenced data series. Thus, we can conclude that all our data series are $I(1)$ in their levels; that is, each series is integrated of order one.

Table 3 presents Johansen's cointegration test results for our variables of concern. The cointegration test is performed for the endogenous Inf, rexch and $y$, using Parity as an exogenous variable. Based on the $\lambda_{\text {trace }}$ statistic, we reject the null hypothesis that the number of distinct cointegrating vectors is zero against the alternative that a larger number of cointegrating vectors exist at the $5 \%$ level of significance. In support of this, we reject, at the 5\% level of significance, the null hypothesis of zero cointegrating vectors against the alternative of one cointegrating vector using the $\lambda_{\max }$ test statistics. Therefore, using both tests, we fail to reject the null hypotheses that one cointegrating vector exists against respective alternatives, whereas we could reject the existence of two cointegrating vectors. Consequently, we conclude that one cointegrating vector exists for our endogenous variables. Eventually, we perform our VAR analysis in logarithmic levels, following Sims et al. (1990).

Based on the findings of Table 3, there is a long-run relationship among our variables of concern. Furthermore, the cross-correlation results that 
Table 2. Augmented Dickey-Fuller test statistics

\begin{tabular}{|c|c|c|c|c|}
\hline & \multicolumn{2}{|c|}{ ADF test in levels } & \multicolumn{2}{|c|}{ ADF test in first differences } \\
\hline & $\begin{array}{l}\text { With constant } \\
\text { without trend }\end{array}$ & $\begin{array}{l}\text { With constant } \\
\text { with trend }\end{array}$ & $\begin{array}{l}\text { With constant } \\
\text { without trend }\end{array}$ & $\begin{array}{l}\text { With constant } \\
\text { with trend }\end{array}$ \\
\hline $\operatorname{Inf}$ & -2.382 & -2.955 & $-17.026^{*}$ & $-16.928 *$ \\
\hline Parity & -0.795 & -1.723 & $-3.731^{*}$ & $-8.966^{*}$ \\
\hline rexch & -1.376 & -1.548 & $-6.719^{*}$ & $-6.703^{*}$ \\
\hline$y$ & -0.309 & -1.504 & $-8.816^{*}$ & $-8.752^{*}$ \\
\hline
\end{tabular}

Notes: *Rejection of the null-hypothesis of a unit-root at the $1 \%$ level of significance. The optimal number of lags of the first difference of the test variable in the ADF test equation is determined by using the modified-Schwarz criterion.

Table 3. Cointegration test among the variables Inf, Rexch and $y$ with the exogenous series Parity

\begin{tabular}{llclrr}
\hline $\begin{array}{l}\text { Hypothesized number of } \\
\text { cointegrating equations }\end{array}$ & Eigen value & $\lambda_{\max }$ & $5 \%$ critical value & $\lambda_{\text {trace }}$ & $5 \%$ critical value \\
\hline None* & 0.467 & 42.83 & 20.97 & 49.28 & 29.68 \\
At most 1 & 0.059 & 4.18 & 14.07 & 6.45 & 15.41 \\
At most 2 & 0.032 & 2.27 & 3.76 & 2.27 & 3.76
\end{tabular}

Notes: *Denotes rejection of the hypothesis at the $5 \%$ level of significance. The critical values are based on Osterwald-Lenum (1992).

are presented in Table 1 show some associations between Parity and the other variables. However, these patterns are not robust for different filters applied to our series. More importantly, these observations neither rule out the possibility of a spurious relationship among our variables nor do they account for the transmission mechanism through which Parity affects the other variables. Therefore, we specify and estimate a VAR model, which has the major advantage of capturing and measuring the effects of external parity shocks properly while accounting for the dynamic relationships among the variables of concern.

\section{Specification of the VAR System}

Our bivariate analysis results do not provide us with a satisfying comprehension of the relationships among our variables. Although we have failed to reject the existence of a long-run association among them, we have not obtained a clear econometric description of such an association. Therefore, we employ a VAR set-up to account for the interaction among the variables under consideration.

We basically use the impulse-response functions to describe the relationships that we are seeking within a VAR set-up. However, the standard form of VAR as used by Sims (1972) has a serious drawback in that the external variables are affected by the domestic variables with lags. That is, we aim to measure the effects of external shocks on an SOE, so the impact of a foreign shock on the domestic economy is important but not vice versa. An 'identified VAR model with block exogeneity' would overcome the above-mentioned problem; it would also be able to specify economically meaningful simultaneous interactions among variables, instead of a complete set of equations lacking economic intuition. The restrictions on the lagged relationships are determined by the data.

The general specification of Cushman and Zha (1997) and Zha (1999), can be used to assess the details of the identified VAR model with block exogeneity:

$$
A(L) z(t)=\varepsilon(t)
$$

In Equation 1, $z(t)$ is an $m \times 1$ vector of observations, $A(L)$ is an $m \times m$ matrix polynomial in the lag operator $L$ and $\varepsilon(t)$ is an $m \times 1$ vector of structural disturbances. The specification in matrix form is as follows:

$$
\begin{aligned}
& z(t)=\left[\begin{array}{l}
z_{1}(t) \\
z_{2}(t)
\end{array}\right], \quad A(L)=\left[\begin{array}{cc}
A_{11}(L) & 0 \\
A_{21}(L) & A_{22}(L)
\end{array}\right], \\
& \varepsilon(t)=\left[\begin{array}{l}
\varepsilon_{1}(t) \\
\varepsilon_{2}(t)
\end{array}\right] .
\end{aligned}
$$

The assumptions of Equation 2 are that the coefficient matrix of $L^{0}$ in $A(L), A_{0}$ is nonsingular and $\varepsilon(t)$ is uncorrelated with $z(t-s)$ for $s>0$. 
In the matrix $A(L), A_{12}(L)$ is zero so as to represent the block exogeneity. This means that the second block $z_{1}(t)$ is exogenous to the first block $z_{2}(t)$ both contemporaneously and for lagged values of the variables. Thus, the maximum likelihood estimation of VAR models as in Sims (1986) and Gordon and Leeper (1994), is not applicable to the identified VAR model with block exogeneity. The maximum likelihood estimation and inference for the second block are computed with the conventional Choleski normalization with the modified error bands of Sims and Zha (1999).

The lag order, suggested by the Schwarz information criterion, of our identified VAR model with block exogeneity is 2, and it is constructed as $z_{1}=[$ Parity $]$ and $z_{2}=[\text { rexch, Inf, } y]^{\prime}$. Therefore, the foreign shock that we are trying to analyse is in the USD-Euro parity. Within this framework, USDEuro parity does not get any feedback from the domestic economy. The reverse is, by definition, valid in that USD-Euro parity does affect the domestic economy. The ordering of the variables in $z_{2}$ is important. Our assumption is that the first variable to be affected by an innovation in parity is the real exchange rate. The second variable in the ordering is inflation, which we assume will not affect the real exchange rate but is affected by the real exchange rate contemporaneously. The last variable in the ordering is output because it is affected by the real exchange rate and inflation contemporaneously, but not vice versa. However, these three variables affect each other with lags. In our specification, we also employ a constant term, and quarterly dummy variables to account for seasonality.

Our VAR specification, except for the inclusion of parity, is the same as that of Kamin and Rogers (2000), who studied the case of Mexico, and Berument and Pasaogullari (2003), who studied the case of Turkey. The above-mentioned ordering of endogenous variables in the VAR follows the same reasoning as proposed in those studies.

\section{Impulse Response Functions: Capturing the Effects of USD-Euro Parity}

The impulse response functions for eight periods computed by using our VAR specifications are reported in Fig. 2. A 1 SD shock is given to parity within the SVAR specification described in Section III. ${ }^{9}$

In Fig. 2, the self-response of parity is positive and statistically significant for seven periods. The real exchange rate, rexch, responds negatively to an innovation in Parity for seven quarters, i.e. a real appreciation of the TL against the USD. Although the illustrative model in Appendix shows the ambiguity of the sign of Parity in the reduced-form real exchange rate equation, this finding does not depict the same ambiguity. The response of Inf to Parity is significantly negative for seven quarters. In other words, when the USD value of the Euro increases, domestic inflation falls, which is consistent with recent developments in the Turkish economy. ${ }^{10}$ The real GDP (y) responds positively to Parity. Its response is statistically significant for six quarters. The responses of rexch and $y$ to Parity are economically meaningful according to our illustrative model in Appendix. Although there is no clear implication about Inf in the same model, the response of Inf to Parity has been clearly revealed by our structural vector auto regressions (SVAR) specification. All these findings are 'intuitively acceptable', since an increase in the USD value of the Euro may cause an increase in the terms of trade, measured as the ratio of the price of exportables to the price of importables. Such an increase improves the trade balance in the short-to-medium term, assuming that the real quantities of exports and imports will not be affected during this same period. ${ }^{11}$ It is clear that such an improvement in the trade balance will also improve output. As far as domestic inflation is concerned, an increase in the USD value of the Euro is associated with the relative cheapening of imported inputs priced in USD terms. In this way, domestic inflation drops significantly.

In order to check for the robustness to crises of our SVAR specification, we replicate the results of Fig. 2 using the three additive dummy variables to control for the occurrence of the two major financial crises in Turkey during the last decade. The first crisis occurred in the second quarter of 1994; the second and third dummies cover the last quarter of 2000 and the first quarter of 2001. The major findings of Fig. 2 do not change, as shown by a visual comparison of Figs 2 and 3 reveals. The negative response of inflation (Inf) is statistically significant for seven

\footnotetext{
${ }^{9}$ We use the conventional 'RATS' Bayesian simulation method based on Sims and Zha (1999) to produce the error bands for the impulse responses, where the error bands are $68 \%$ bands from the Bayesian procedure.

${ }^{10}$ Starting at the end of 2001, the rate of inflation in Turkey displayed a noticeable decline; this was the key target of the latest stabilization package, which was also supported by the IMF. It is believed that the parity developments in international foreign exchange markets partly support this disinflation process.

${ }^{11}$ See Berument and Dincer (2005) on the effects of USD-Euro parity on the trade balance.
} 

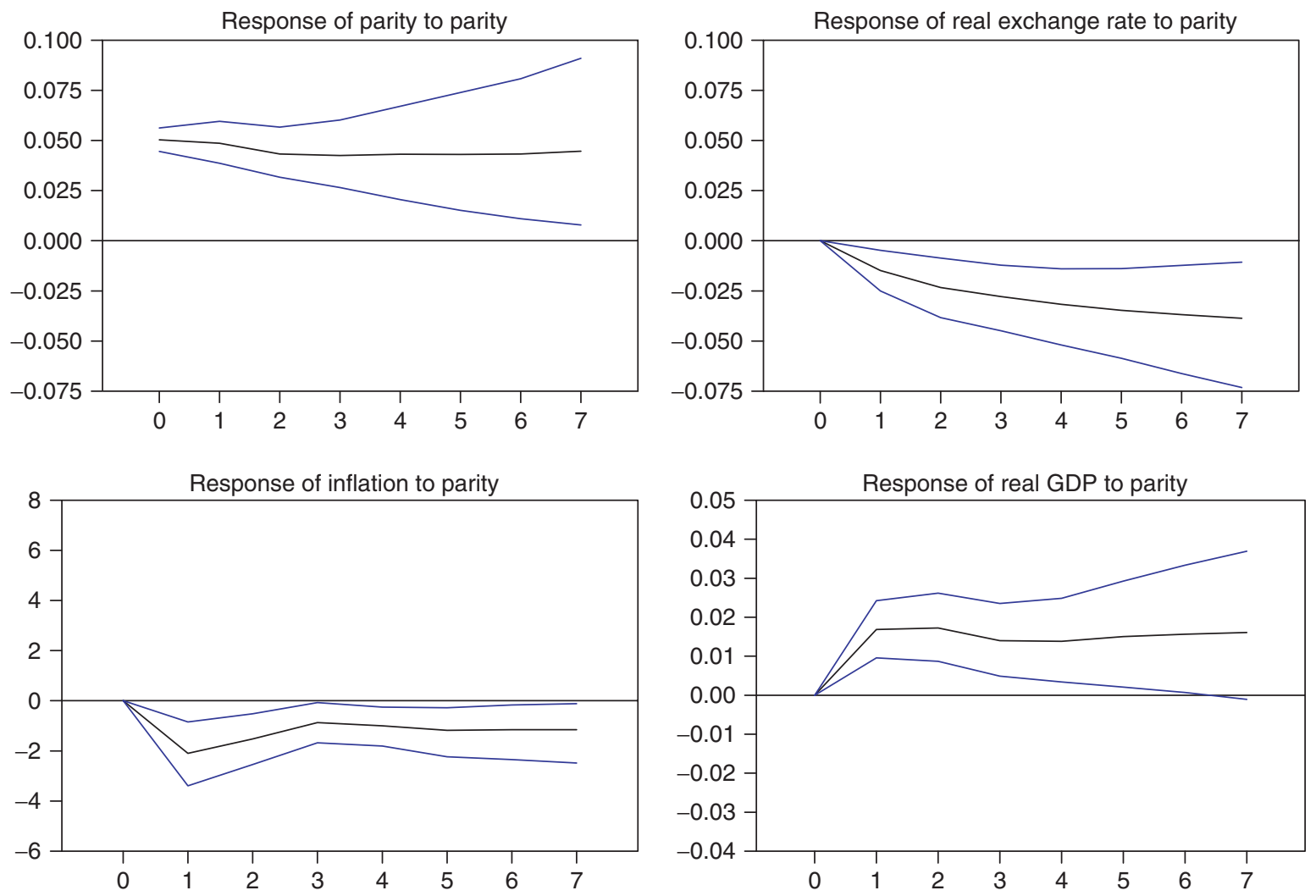

Fig. 2. Impulse-response functions

Notes: The central line in each panel presents the impulse-response function. The envelopes are the $68 \%$ error bands obtained from the Bayesian procedure, based on Sims and Zha (1999).

quarters (with the exception of the third quarter) and the positive response of the real GDP $(y)$ is statistically significant for five quarters. The negative response of rexch to Parity runs from the second to the seventh period following the Parity innovation. Therefore, we can say that the impulse-responses are robust even with the inclusion of crisis dummy variables. ${ }^{12}$

\section{Conclusion}

This article uses Turkish data to examine how changes in USD-Euro parity affect the economic performance of an SOE with different currency compositions of exports and imports. This research question is especially relevant since the relative movements of two of the world's major currencies may have unidirectional and sizable effects on an SOE, such as Turkey. These effects will be through the channels of real exchange rate and/or the terms of trade, where these two are neither totally overlapping, nor mutually exclusive. Regardless of the channel, net exports and output will eventually respond to changes in relative trade prices. An unbalanced currency composition of trade can be viewed as a pre-condition for this last statement. Since USDEuro parity is an important exogenous variable for Turkey, we focus on its effects in this study; the empirical evidence suggests that inflation drops and output increases follow positive parity innovations, the real exchange rate being negatively affected by USD-Euro parity.

The econometrics of the feedback from USD-Euro parity on the Turkish economy is carried out within a VAR system with block exogeneity. This approach particularly suits the case at hand, owing to the oneway nature of the feedback. That is, USD-Euro parity will have effects on an SOE but causality in the opposite direction never happens. Our results are

\footnotetext{
${ }^{12}$ The sensitivity exercise that we carried out using binary dummy variables is more mechanical in its nature; i.e. we want to control for any possible breaks in the estimated VAR relationship, without specific reference to the literature.
} 

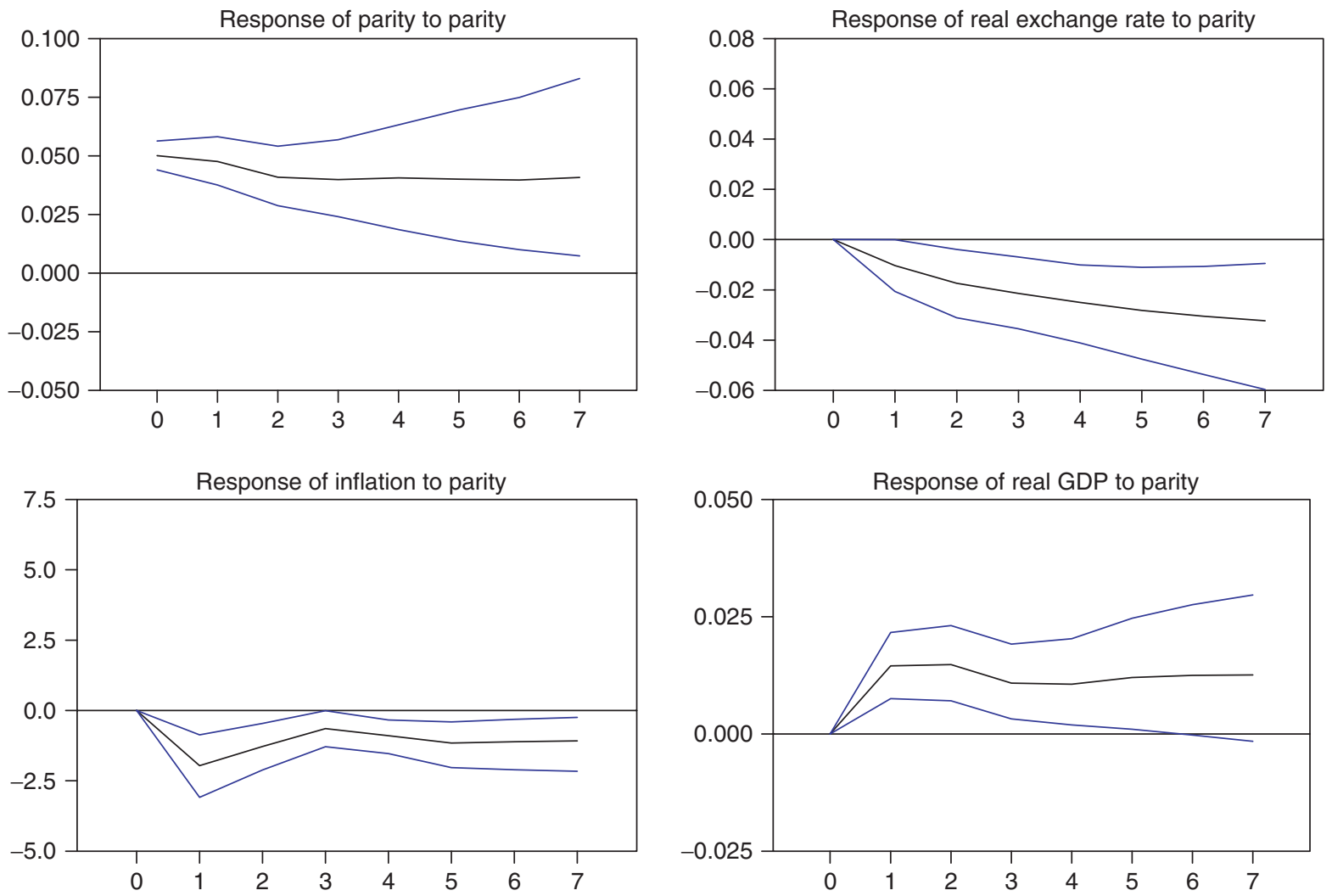

Fig. 3. Impulse-response functions: with crisis dummies

Notes: The central line in each panel shows the impulse-response function. The envelopes are the $68 \%$ error bands obtained from the Bayesian procedure, based on Sims and Zha (1999).

robust up to the inclusion of crisis dummies and the terms of trade in the VAR set-up.

The impact of our findings is considerable since Turkey, as an SOE, establishes a benchmark example for similar economies with regard to changes in USD-Euro parity. The extent of the exposure of an SOE to the relative movements of two major currencies is clearly depicted. The fundamental conclusion of this study, hence, is that macroeconomic policies should be dependent on external parity shocks originating from the world's major currencies.

\section{Acknowledgements}

All the views expressed in this article are those of the authors and do not necessarily reflect those of the Central Bank of the Republic of Turkey, or its staff. We would like to thank Tao Zha for providing his computer programs and Ugur Ciplak for his support in gathering part of the data set. We would also like to thank Anita Akkas, Yelda Celikoglu and the participants of the Pazar11 discussion group for their helpful suggestions.

\section{References}

Akinlo, A. E. and Odusola, A. F. (2003) Assessing the impact of Nigeria's naira depreciation on output and inflation, Applied Economics, 35, 691-703.

Berument, H., Ceylan, N. B. and Vural, B. (2006) The effects of Japanese economic performance on Indonesia, Applied Economics Letters, 13, 499-502.

Berument, H. and Dincer, N. (2005) Denomination composition of trade and trade balance: evidence from Turkey, Applied Economics, 37, 1177-91.

Berument, H. and Pasaogullari, M. (2003) Effects of the real exchange rate on output and inflation: evidence from Turkey, Developing Economies, 41, 401-35.

Christopoulos, D. K. (2004) Currency devaluation and output growth: new evidence from panel data analysis, Applied Economics Letters, 11, 809-13.

Cushman, D. and Zha, T. (1997) Modifying monetary policy in a small open economy under flexible exchange rates, Journal of Monetary Economics, 39, 433-48.

Gordon, D. B. and Leeper, E. M. (1994) The dynamic impacts of monetary policy: an exercise in tentative identification, Journal of Political Economy, 102, 1228-1247.

IMF (2001) World Economic Outlook, May.

IMF (2002) World Economic Outlook, April. 
Kamin, R. (1996) Exchange rates and inflation in exchange rate-based stabilizations: an empirical examination, International Finance Discussion Paper No. 554, Board of Governors of the Federal Reserve System, Washington, DC.

Kamin, S. B. and Rogers, J. H. (2000) Output and the real exchange rate in developing countries: an application to Mexico, Journal of Development Economics, 61, 85-109.

Osterwald-Lenum, M. (1992) A note with quantiles of the asymptotic distribution of the maximum likelihood cointegration rank test statistics, Oxford Bulletin of Economics and Statistics, 54, 461-72.

Sims, C. A. (1972) Money, income, and causality, The American Economic Review, 62, 540-52.

Sims, C. A. (1986) Are forecasting models usable for policy analysis?, Quarterly Review of the Federal Reserve Bank of Minneapolis, 10, 2-16.

\section{Appendix: An Illustrative Model}

In this appendix, we elaborate on the structural framework employed by Kamin and Rogers (2000), to capture the effects of USD-Euro parity on economic performance. In our model, total GDP $(Y)$ is composed of two components: the domestic demand $(D D)$ and net exports $(N X)$ as given in Equation A1:

$$
Y=D D+N X
$$

In Equation A2, net exports is related positively to the real exchange rate, RER (defined such that an increase indicates real depreciation of currency), negatively to output $(Y)$ and negatively to USDEuro parity (Parity), defined as the number of Euros per USD:

$$
N X=a_{21} R E R-a_{22} Y-a_{23} \text { Parity }
$$

In Equation A3, domestic demand is affected by real interest rate $(r)$, fiscal deficit (FISCDEF), the real stock bank credits (RCREDIT), the nominal interest rate $(i)$, the inflation rate $(\pi)$, the real exchange rate $(R E R)$ and the real wage $(R W)$. As real exchange rate affects net exports positively, additional effects on aggregate demand are assumed to be negative:

$$
\begin{aligned}
D D= & -a_{31} r+a_{32} \text { FISCDEF }+a_{33} R C R E D I T \\
& -a_{34} i-a_{35} \pi-a_{36} R E R+a_{37} R W-a_{38} \text { Parity }
\end{aligned}
$$

In Equation A4, the supply of bank credit is explained by the bank's main sources of funds, namely the real domestic money $(R M)$ and foreign borrowing proxied by private capital flows $(K A)$ :

$$
R C R E D I T=a_{41} R M+a_{42} K A
$$

Sims, C. A. and Zha, T. (1998) Does monetary policy generate recessions?: using less aggregated price data to identify monetary policy, Federal Reserve Bank of Atlanta, Working Paper, 98-12.

Sims, C. A. and Zha, T. (1999) Error bands for impulse responses, Econometrica, 67, 1113-55.

Sims, C. A., Stock, J. H. and Watson, M. W. (1990) Inference in linear time series models with some unit roots, Econometrica, 58, 113-44.

Spatafora, N. (2003) How concerned should developing countries be about G-3 exchange rate volatility, World Economic Outlook, September, 92-111.

Upadhyaya, K. P., Mixon Jr F. G. and Bhandari, R. (2004) Exchange rate adjustment and output in Greece and Cyprus: evidence from panel data, Applied Financial Economics, 14, 1181-5.

Zha, T. (1999) Block recursion and structural vector autoregressions, Journal of Econometrics, 90, 291-316.

Equation A5 depicts the standard money demand function:

$$
R M=a_{51} Y-a_{52} i
$$

The central bank's reaction function is supposed to have the following form where it includes inflation $(\pi)$, output $(Y)$ and capital flows $(K A)$.

$$
i=a_{61} \pi+a_{62} Y-a_{63} K A
$$

Equation A7 presents the CPI inflation rate as in Kamin (1996). It is determined by real exchange rate $(R E R)$, output $(Y)$ and the rate of nominal exchange rate depreciation $\left(E^{\prime}\right)$.

$$
\pi=a_{71} R E R+a_{72} Y+a_{73} E^{\prime}
$$

Equation A8 is the interest parity condition. Net capital flows $(K A)$ is determined by the nominal interest rate $(i)$, the rate of nominal exchange rate $\left(E^{\prime}\right)$ and the US interest rate $\left(i^{\mathrm{US}}\right)$.

$$
K A=a_{81} i-a_{82} E^{\prime}-a_{83} i^{\mathrm{US}}
$$

In Equation A9, exchange rate depreciation is defined as a function of domestic inflation $(\pi)$, foreign inflation $\left(\pi^{\mathrm{US}}\right)$ and real exchange rate $(R E R)$.

$$
E^{\prime}=a_{91} \pi-a_{92} \pi^{\mathrm{US}}+a_{93} R E R
$$

In Equation A10, balance of payments pressures drive the real exchange rate:

$$
R E R=-a_{101} N X-a_{102} K A
$$

The noninterest fiscal deficit (FISCDEF) declines in response to an increase in output, $Y$, reflecting higher tax revenues. Increases in net capital inflows $(K A)$ are assumed to raise the fiscal deficit because they allow the government both to borrow more abroad and to pursue less austere policies. Higher inflation 
$(\pi)$ prompts the government to tighten its fiscal policies.

$$
F I S C D E F=-a_{111} Y+a_{112} K A-a_{113} \pi
$$

Real wages $(R W)$ depend positively on output $(Y)$ but negatively on inflation $(\pi)$ following the contractionary devaluation hypothesis.

$$
R W=a_{121} Y-a_{122} \pi
$$

By substituting the endogenous variables, the 12-equation system reduces to a three-equation system that we call the core model:

$$
\begin{gathered}
\pi=a_{11}^{\prime} R E R-a_{12}^{\prime} Y-a_{13}^{\prime} \pi^{\mathrm{US}} \\
R E R=a_{21}^{\prime} Y-a_{22}^{\prime} \pi-a_{23}^{\prime}{ }^{\mathrm{US}}-a_{24}^{\prime} \pi^{\mathrm{US}}-a_{25}^{\prime} \text { Parity } \\
Y=-a_{31}^{\prime} r+a_{32}^{\prime} \pi^{\mathrm{US}}+a_{33}^{\prime} \pi-a_{34}^{\prime} i^{\mathrm{US}} \\
-a_{35}^{\prime} R E R+a_{36}^{\prime} \text { Parity }
\end{gathered}
$$

The coefficients in Equations A13, A14 and A15 are not straightforward; i.e. they are complicated combinations of the coefficients of our illustrative model. Thus, we have written our 'prior view' as to the signs of those coefficients whenever they are ambiguous; where each $a_{i j}$ in Equations A13-A15 is positive and the signs in front show the direction of the relationship. Having focused on the signs of Parity in Equations A14 and A15, we can say that its sign is negative in Equation A14 and positive in Equation A15. This prior view is due to two points. First, as USD-Euro parity increases, there is an increase in the terms of trade, namely in the price of exportables over the price of importables. Since the real trade flows will not be affected in the short term, net exports improve, as does the output. Second, an increase in Parity has recently caused a relative appreciation of the Turkish lira against the USD; since we measure the real exchange rate as the WPI deflated TL value of the USD, we can expect Parity to inversely affect $R E R$.

Finally, Parity does not appear in Equation A13, yet it affects inflation indirectly through its effects on the RER and $Y$, as mentioned above. 